\title{
WATER QUALITY IN THE NORTH MADURA : IS IT SUITABLE FOR VANNAMEI SHRIMP FARMING OR NOT?
}

\author{
Muhammad Browijoyo Santanumurti $^{1}$. Syifania Hanifah \\ Samara $^{1}$. Daruti Dinda Nindarwi ${ }^{1}$
}

Ringkasan Indonesia is one of the countries with the highest potential and production of vannamei shrimp (Litopenaues vannamei) in the world. Therefore, the government continues to improve the activity of vannamei shrimp farming continuously. This study aimed to determine whether the water quality of the waters in Larangan Glintong Village, Bangkalan-Madura, East Java was suitable for vannamei shrimp farming activities. Water quality was one of the keys for successful vannamei shrimp farming since it could affect the metabolism, reproduction, osmoregulation and stress of the organism. The parameter water quality used in this study was salinity, temperature, and $p H$. This research was a water quality survey that was carried out for three months (March-May). The result showed that the average water salinity was 30.5 ppt. The average temperature in the North Madura was 29.41oC and 8.13 while the $p H$ valued showed 8.13. It could be concluded that ponds in Nor-

\footnotetext{
$\left.{ }^{1}\right)$ 1Departemen Manajemen Kesehatan Ikan dan Budidaya Perairan, Fakultas Perikanan dan Kelautan, Universitas Airlangga, Surabaya 60115

E-mail: dnindarwi@gmail.com
}

th Madura could be used for optimum vannamei aquaculture.

Keywords vannamei shrimp, salinity, temperature, $p H$, North Madura

Received : 12 September 2019

Accepted :23 Oktober 2019

\section{PENDAHULUAN}

Indonesia merupakan salah satu negara dengan potensi perikanan udang terbesar di dunia. Pada tahun 2014, Indonesia merupakan negara produsen udang tertinggi kedua di dunia dengan total produksi mencapai 598.000 ton (Saputri, 2017). Salah satu komoditas udang utama di Indonesia dalah udang vaname (Litopenaeus vannamei). Udang vaname termasuk komoditas ekonomis penting karena pertumbuhannya cepat, kelulushidupannya tinggi, tidak mudah terserang penyakit dan banyak dibudidayakan di seluruh dunia (Li et al., 2016; Mahasri et al., 2019). Udang vaname berkontribusi sebanyak $40 \%$ dari seluruh hasil perikanan dan perolehan devisa (Hadie and Hadie, 2017). Oleh karena itu pemerintah mengupayakan peningkatan dan perkembangan produksi 
udang vaname melalui aktivitas budidaya.

Salah satu aspek penting dalam budidaya udang adalah kualitas air. Kualitas air dapat mempengaruhi kesehatan dan tingkat stres komoditas budidaya sehingga kualitas air yang buruk dapat menimbulkan penyakit (Devi et al., 2017). Sebagai contoh suhu air optimal $\left(29-31^{\circ} \mathrm{C}\right)$ akan meningkatkan pertumbuhan dan nafsu makan udang vaname (Tacon et al., 2013). Apabila suhu tidak berada pada angka optimum, udang yang dipelihara dapat mengalami pertumbuhan yang lambat, bahkan kematian. Pada laporan sebelumnya di Meksiko, udang mengalami kematian hingga $80 \%$ karena fluktuasi suhu yang diakibatkan oleh hujan (Tendencia et al., 2011). Penelitian sebelumnya juga menunjukkan bahwa pada suhu rendah, respon udang vaname akan menjadi lambat dan tumbuh tidak optimal (Kumlu et al., 2010). Parameter kualitas air diantaranya adalah suhu, $\mathrm{pH}$, salinitas, DO, kecerahan dan tinggi air (Poonkodi et al., 2016; Liu et al., 2017).

Pengukuran kualitas air sangat penting untuk menentukan apakah suatu tempat cocok untuk kegiatan budidaya, termasuk udang vaname. Penelitian ini bertujuan untuk mengetahui kualitas air kolam di daerah Desa Larangan Glintong, Klampis, Bangkalan, Madura. Kualitas air yang baik dapat digunakan sebagai indikator bahwa kolam tersebut dapat dioptimalkan sebagai media kegiatan pembesaran udang vaname.

\section{MATERI DAN METODE}

Lokasi penelitian ini terletak di Desa Larangan Glintong, Klampus, Bangkalan, Madura, Jawa Timur seperti yang

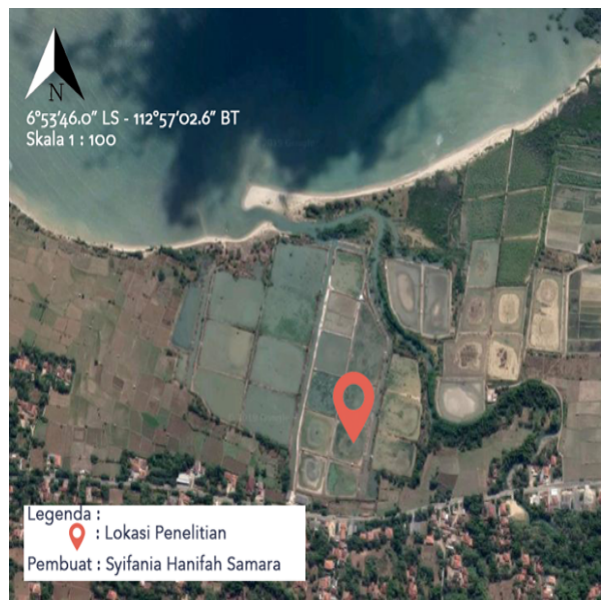

Gambar 1 Lokasi penelitian di Desa Larangan Glintong, Klampis, Bangkalan, Jawa Timur

terlihat pada Gambar 1. Pengambilan sampel air diambil dari calon kolam tambak udang vanname dengan koordinat 6 53'46.0" LS, 112 $57^{\circ}$ '02.6" BT. Penelitian ini dilaksanakan selama 3 bulan, dari bulan Maret hingga Mei 2018.

Parameter kualitas air yang digunakan adalah suhu, $\mathrm{pH}$, salinitas dan kecerahan. Pemilihan parameter kualitas air tersebut berdasarkan penelitian yang telah dilakukan sebelumnya (Ajin et al., 2016). Pengukuran suhu dan $\mathrm{pH}$ menggunakan YSI Pro20 dissolved oxygen meter (YSI, US) dan digital $\mathrm{pH}$ meter (YSI, US) (Farmer et al., 2017). Pengukuran dilaksanakan setiap hari pada jam 6 pagi dan 1 siang.

\section{HASIL DAN PEMBAHASAN}

Data kualitas air menunjukkan bahwa rata-rata salinitas pada bulan Maret Mei adalah 30,5 ppt. Rata-rata salinitas tertinggi terjadi pada bulan Mei dengan nilai 33,7 ppt sementara rata-rata salinitas paling rendah terjadi pada bulan Maret dengan nilai 28,73 ppt. Ratarata salinitas air mingguan dari bulan Maret hingga Mei adalah 28,86-35 ppt. 


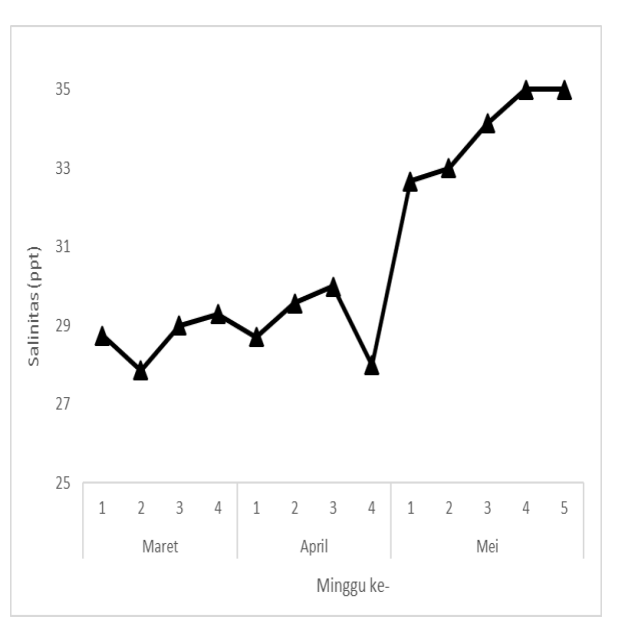

Gambar 2 Salinitas air di Desa Larangan Glintongpada bulan Maret - Mei

Data salinitas mingguan dalam 3 bulan (Maret-Mei) dapat dilihat pada Gambar 2 .

Hasil kualitas air menunjukkan bahwa salinitas di Desa Larangan Glintong cocok untuk budidaya udang vaname. Menurut penelitian sebelumnya $30 \mathrm{ppt}$ merupakan salinitas yang terbaik jika dibandingkan dengan salinitas rendah. Penelitian tersebut menunjukkan bahwa pada salinitas tersebut kelulushidupan post-larvae mencapai $100 \%$ dan pertumbuhannya optimal (Laramore et al., 2001). Hal ini dikarenakan salinitas lingkungan berpengaruh terhadap osmoregulasi, metabolisme dan ekskresi nitrogen makhluk hidup, termasuk udang (Urbina and Glover, 2015). Rendahnya salinitas akan mengganggu enzim yang berhubungan dengan transport $\mathrm{Na}+/ \mathrm{K}+-$ ATPase dan V-ATPase (Ramaglia et al., 2018).

Data kualitas air menunjukkan bahwa rata-rata suhu pada bulan Maret - Mei adalah $29,41^{\circ} \mathrm{C}$. Rata-rata salinitas tertinggi terjadi pada bulan April dengan nilai $30,05^{\circ} \mathrm{C}$ sementara rata-rata suhu paling rendah terjadi pada bulan Mei dengan nilai $28,73^{\circ} \mathrm{C}$. Rata-rata suhu

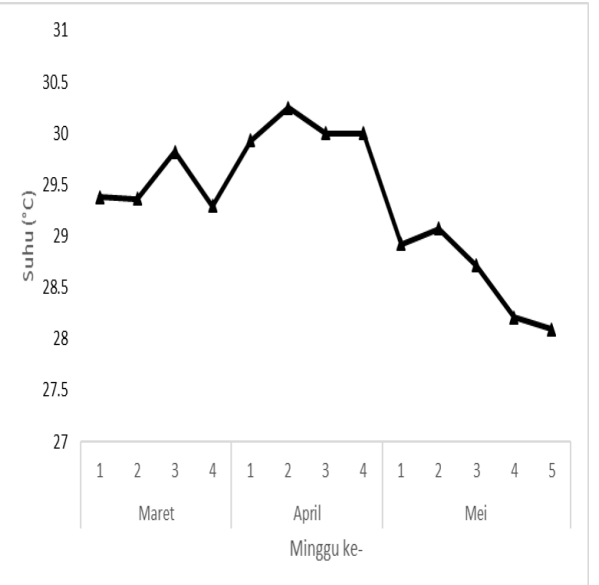

Gambar 3 Suhu air di Desa Larangan Glintong pada bulan Maret - Mei

air mingguan dari bulan Maret hingga Mei adalah $28,21-30,25^{\circ} \mathrm{C}$. Data suhu perminggu dalam 3 bulan (Maret-Mei) dapat dilihat pada Gambar 3.

Suhu adalah salah satu faktor yang terpenting dalam budidaya udang. Suhu perairan di daerah Madura Utara merupakan suhu yang optimal untuk kegiatan budidaya udang vaname. Menurut penelitian sebelumnya, suhu $28-30^{\circ} \mathrm{C}$ merupakan suhu yang paling baik untuk pertumbuhan dan kelulushidupan udang vaname (Ponce-Palafox et al., 1997). Hal ini dikarenakan suhu sesuai dengan lingkungan dapat menurunkan penggunaan energi, menjaga kandungan lipid pada udang dan menjaga kerja metabolisme tubuh (Tropea et al., 2015).

Data kualitas air menunjukkan bahwa rata-rata $\mathrm{pH}$ pada bulan Maret - Mei adalah 9,13. Rata-rata $\mathrm{pH}$ tertinggi terjadi pada bulan Mei dengan nilai 8,28 sementara rata-rata $\mathrm{pH}$ paling rendah terjadi pada bulan April dengan nilai 7,91. Rata-rata $\mathrm{pH}$ air mingguan dari bulan Maret hingga Mei adalah 7,88,44 . Data $\mathrm{pH}$ perminggu dalam 3 bulan (Maret-Mei) dapat dilihat pada Gambar 4. 


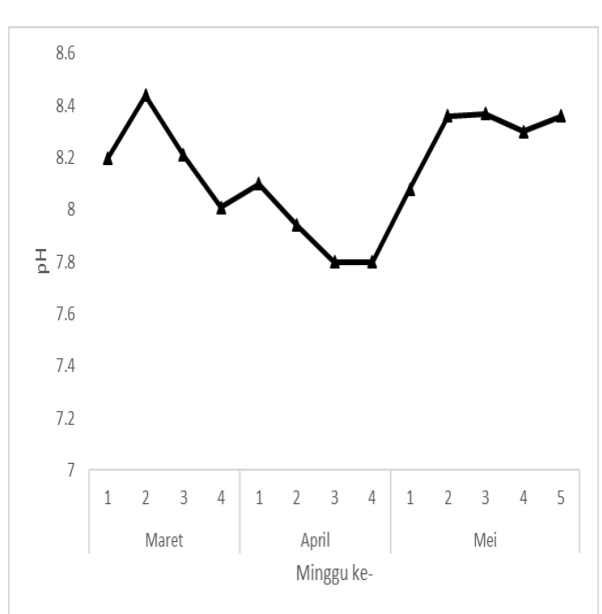

Gambar 4 pH air di Desa Larangan Glintong pada bulan Maret - Mei

Hasil pengukuran kualitas air menunjukkan bahwa $\mathrm{pH}$ di Desa Larangan Glintong cocok untuk budidaya udang vaname. $\mathrm{pH}$ terbaik untuk pertumbuhan udang adalah antara 7-9 (Zhang et al., 2017). Perubahan $\mathrm{pH}$ yang tidak sesuai dengan kondisi optimal udang dapat mempengaruhi osmoregulasi, jumlah sel, metabolisme dan transpor oksigen pada makhluk hidup. Pada udang, apabila $\mathrm{pH}$ turun maka oksigen yang diserap akan turun (Maqsood and Benjakul, 2011). Hal ini dikarenakan penurunan $\mathrm{pH}$ akan mengurangi afinitas pigmen pernapasan pada udang untuk yang berfungsi dalam suplai oksigen yang dikenal dengan efek Bohr (Ramaglia et al., 2018). Oleh karena itu udang akan mengeluarkan energi lebih untuk mensuplai oksigen sehingga energi yang seharusnya digunakan untuk tumbuh berkurang.

\section{SIMPULAN}

Kolam di Desa Larangan Glintong, Klampis, Bangkalan-Madura, Jawa Timur cocok digunakan untuk aktivitas budidaya udang vaname (Litopenaes vanna- $m e i)$. Hal ini dikarenakan salinitas, suhu dan $\mathrm{pH}$ di perairan tersebut sesuai dengan lingkungan hidup optimal udang vaname.

\section{Pustaka}

Ajin, A., Silvester, R., Alexander, D., Nashad, M., and Abdulla, M. H. (2016). Characterization of blooming algae and bloom-associated changes in the water quality parameters of traditional pokkali cum prawn fields along the south west coast of india. Environmental monitoring and assessment, 188(3):145.

Devi, P. A., Padmavathy, P., Aanand, S., and Aruljothi, K. (2017). Review on water quality parameters in freshwater cage fish culture. International Journal of Applied Research, 3(5):114-120.

Farmer, B. D., Beck, B. H., Mitche11, A. J., Rawles, S. D., and Straus, D. L. (2017). Dietary copper effects survival of channel catfish challenged with flavobacterium columnare. Aquaculture research, 48(4):1751-1758.

Hadie, W. and Hadie, L. E. (2017). Analisis sistem budidaya untuk mendukung kebijakan keberlanjutan produksi udang. Jurnal Kebijakan Perikanan Indonesia, 9(1):51-60.

Kumlu, M., Kumlu, M., and Turkmen, S. (2010). Combined effects of temperature and salinity on critical thermal minima of pacific white shrimp litopenaeus vannamei (crustacea: Penaeidae). Journal of Thermal Biology, 35(6):302-304.

Laramore, S., Laramore, C. R., and Scarpa, J. (2001). Effect of low salinity on growth and survival of post- 
larvae and juvenile litopenaeus vannamei. Journal of the World Aquaculture Society, 32(4):385-392.

Li, W., Lu, X., Luan, S., Luo, K., Sui, J., and Kong, J. (2016). Heritability of body weight and resistance to ammonia in the pacific white shrimp litopenaeus vannamei juveniles. Chinese Journal of Oceanology and Limnology, 34(5):10251033.

Liu, X., Xu, H., Cheng, G., Liu, C., Liu, S., Lu, S., Tian, C., Tang, R., and $\mathrm{Gu}, \mathrm{Z}$. (2017). Effects of portable solar water quality control machines on aquaculture ponds. Environmental Science and Pollution Research, 24(4):4040-4047.

Mahasri, G., Heryamin, A., and Kismiyati, K. (2019). Prevalensi ektoparasit pada udang vaname (litopenaeus vannamei) dengan padat tebar yang berbeda di tempat penggelondongan di kabupaten gresik. Journal of Aquaculture and Fish Health, 5(2):4955.

Maqsood, S. and Benjakul, S. (2011). Comparative studies on molecular changes and pro-oxidative activity of haemoglobin from different fish species as influenced by ph. Food Chemistry, 124(3):875-883.

Ponce-Palafox, J., Martinez-Palacios, C. A., and Ross, L. G. (1997). The effects of salinity and temperature on the growth and survival rates of juvenile white shrimp, penaeus vannamei, boone, 1931. Aquaculture, 157(1-2):107-115.

Poonkodi, A., Padmavathy, P., Srinivasan, A., Shakila, R., Anand, T., et al. (2016). Water quality characteristics of litopenaeus vannamei shrimp culture systems in thoothukudi district. Journal of Experimen- tal Zoology, India, 19(1):195-200.

Ramaglia, A. C., de Castro, L. M., and Augusto, A. (2018). Effects of ocean acidification and salinity variations on the physiology of osmoregulating and osmoconforming crustaceans. Journal of Comparative Physiology B, 188(5):729-738.

Saputri, K. (2017). Peluang dan kendala ekspor udang indonesia ke pasar jepang. eJournal Ilmu Hub. Int, 5(4):1179-1194.

Tacon, A. G., Jory, D., Nunes, A., et al. (2013). Shrimp feed management: issues and perspectives. On-farm feeding and feed management in aquaculture, 583:481-488.

Tendencia, E. A., Verreth, J. A., et al. (2011). Temperature fluctuation, low salinity, water microflora: risk factors for wssv outbreaks in penaeus monodon. Israeli Journal of Aquaculture-Bamidgeh, 63:1-7.

Tropea, C., Stumpf, L., and Greco, L. S. L. (2015). Effect of temperature on biochemical composition, growth and reproduction of the ornamental red cherry shrimp neocaridina heteropoda heteropoda (decapoda, caridea). PloS one, 10(3):e0119468.

Urbina, M. A. and Glover, C. N. (2015). Effect of salinity on osmoregulation, metabolism and nitrogen excretion in the amphidromous fish, inanga (galaxias maculatus). Journal of Experimental Marine Biology and Ecology, 473:7-15.

Zhang, K., Pan, L., Chen, W., and Wang, C. (2017). Effect of using sodium bicarbonate to adjust the ph to different levels on water quality, the growth and the immune response of shrimp litopenaeus vannamei reared in zero-water exchange bioflocbased culture tanks. Aquaculture re- 
search, 48(3):1194-1208. 